\title{
Preventive Medicine using Impedimetric Biosensors: Early Detection of Cancer
}

\author{
Mustafa Yuksel $^{1}$, Oguz Hanoglu² and Mustafa Yavuz ${ }^{3 *}$ \\ ${ }^{1}$ Turgut Özal University, School of Health, Department of Audiology, Ankara 06800, Turkey \\ ${ }^{2}$ Istanbul Kemerburgaz University, Computer Engineering, 34217, Istanbul, Turkey \\ ${ }^{3}$ Waterloo Institute for Nanotechnology (WIN), University of Waterloo, Canada
}

\begin{abstract}
Received: October 04, 2015; Accepted: October 06, 2015; Published: October 09, 2015
*Corresponding author: Mustafa Yavuz, Waterloo Institute for Nanotechnology (WIN), University of Waterloo, ON, Canada, Tel: +1-519-8884567; E-mail: myavuz@uwaterloo.ca
\end{abstract}

As known, cancer is a highly specific disease, causing genetic alternations, and resulting in cells to divide without control, and spreading into other tissues and organs. Despite the vast amount of on-going research to find a hope, cancer is still a leading cause of death in today's world. It has been reported that: a total of 1,596,670 new cases of cancer with 571,950 projected deaths for the year 2011 in the United States alone [1]. Worldwide, $12.5-13 \%$ of the deaths are caused by cancer, more than the total percentage of deaths from AIDS, malaria and tuberculosis combined. It has been reported that 7.6 million people died because of cancer in 2008. Although, the overall number of cancer patients and those dying from the disease have declined over the past decade, cancer still continues to be a major threat with over 11 million projected deaths worldwide in 2030 [2,3]. Unfortunately, current technology on cancer diagnosis and treatment is unable to help millions of cancer patients who are looking for a hope [3-5]. According to the World Health Organization (WHO), existing modalities for cancer management can prevent only up to one-third of new cancer cases. The rest two-third needs to be dealt with strategies that integrate early detection with effective treatment measures [6]. Cancer is an uncontrolled and abnormal cell growth that leads to the formation of a tumor mass. This tumor progresses and over time it turns out to a fatal risk by spreading to the other parts of the body. This is called metastasis. After metastasis, it is very difficult to remove cancer cells from the body and cure the cancer patient [4]. This is the reason why early cancer detection is extremely important to deal with it. Figure 1.1 illustrates the incidence and mortality numbers worldwide in the year 2008. The numbers are given for the five cancer diseases (pancreas, liver, lung, oesophagus and gallbladder) with the highest mortality/incidence rates. Pancreas cancer, for example, has the rate of $95.7 \%$ which indicates how helpless we are in treating this cancer.

According to the US National Cancer Institute, nanotechnology promises to achieve significant breakthroughs in the fields of cancer diagnosis, treatment and prevention. Nanoscale objects such as nanoparticles and quantum dots are smaller than the

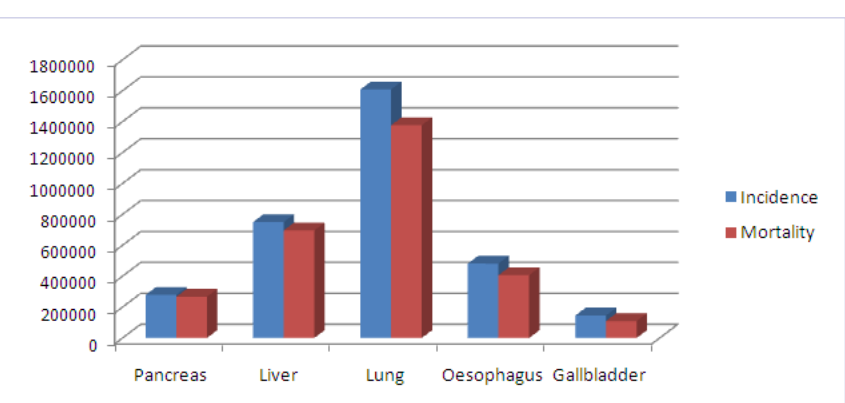

Figure 1.1: Incidence and mortality numbers of the five cancer diseases with highest mortality/incidence rates in 2008 [2].

human cells (5-10 $\mu \mathrm{m}$ in diameter) and can readily interact with biomolecules on both the cell surface and within the cell. These molecular level interactions provide useful information for monitoring complex cellular processes including the onset of biomolecular transformations leading towards cancer metastasis. The surface of nanoparticles can be modified with appropriate ligands to target tumor cells with high specificity and affinity and are used extensively for delivering therapeutic drugs and imaging contrast agents to the cancer cells while sparing the normal healthy cells. Surface modifications render nanoparticles biocompatible and reduce toxicity levels, which is crucial for in vivo applications. Applications of nanotechnology for cancer management involve the use of nanoparticles for detecting cancer at its earliest stages, precisely locating its position within the body, delivering anticancer drugs, specifically to malignant cells, and determining if these drugs are killing the malignant cells. Figure 1-1 summarizes the cancer nanotechnology applications through molecular tumor imaging, early detection, molecular diagnosis, targeted therapy, and bioinformatics [7]. Early detection can be achieved by monitoring the human body for certain cancer biomarkers. These biomarkers can be of various molecular origins depending on the specific cancer. (i.e., proteins, DNA/RNA) Cancer biomarkers are great tools not only for early detection ofcancer; but also monitoring the progress of a cancer treatment [4]. 
Several biomarkers associated with various cancer diseases have been discovered so far, some of which are illustrated in Table 1.1. There is a correlation between the high amount of cancer biomarkers in the human body with related cancer. For example, the risk for prostate cancer is indicated by an elevating levels of Prostate Specific Antigen (PSA) in human blood.

Cancer biomarkers with thresholds in human serum are shown in Table 1.2. In this table 1.2, some biomarker thresholds are given in units/liter (U/L). The unit is an arbitrary amount related to a specific bio-cancer agreed upon by doctors and scientists. They can be converted to gram/liter using the conversion factors associated to each biomarker.

The exact mechanisms beyond the cancer and its metastasis are still not known, however, early detection (before metastasis)

Table 1.1: Biomarkers associated with cancer diseases [8].

\begin{tabular}{|l|c|}
\hline Cancer type disease & Biomarker \\
\hline Prostate & PSA,PAP \\
\hline Breast & $\begin{array}{r}\text { CA15-3,CA125,CA27.29,CEA, BRCA1,BRCA2, } \\
\text { MUC-1,CEA,NY-BR-1,ING-1 }\end{array}$ \\
\hline Leukaemia & \begin{tabular}{c} 
Chromosomal abnormalities \\
\hline Testicular
\end{tabular} \\
\hline Ovarian & $\begin{array}{r}\alpha \text {-Fetoprotein(AFP), } \beta \text {-human chorionic } \\
\text { gonadatropin, CAGE-1, ESO-1 }\end{array}$ \\
\hline Any solid tumor & $\begin{array}{c}\text { CA125, AFP, hCG, p53, CEA } \\
\text { fluids, expression of targeted growth factor } \\
\text { receptors }\end{array}$ \\
\hline Colon and pancreatic & CEA, CA19-9, CA24-2, p53 \\
\hline Lung & $\begin{array}{r}\text { NY-ESO-1, CEA, CA19-9, SCC, CYFRA21-1, } \\
\text { NSE }\end{array}$ \\
\hline Melanoma & Tyrosinase, NY-ESO-1 \\
\hline Liver & AFP, CEA \\
\hline Gastric carcinoma & CA72-4, CEA, CA19-9 \\
\hline Esophagus carcinoma & SCC \\
\hline Trophoblastic & SCC,hCG \\
\hline Bladder & BAT, FDP, NMP22, HA-Hasi, BLCA-4, \\
\hline
\end{tabular}

Table 1.2 : Cancer biomarkers and their threshold levels in human serum [8].

\begin{tabular}{|l|c|c|c|}
\hline $\begin{array}{l}\text { Cancer } \\
\text { biomarkers }\end{array}$ & Thresholds & $\begin{array}{c}\text { Cancer } \\
\text { biomark- } \\
\text { ers }\end{array}$ & Thresholds \\
\hline NSE & $12.5 \mathrm{mg} / \mathrm{L}$ & CEA & $3 \mu \mathrm{g} / \mathrm{L}$ \\
\hline PSA & $4 \mu \mathrm{g} / \mathrm{L}$ & $\mathbf{C A 1 2 5}$ & $35 \mathrm{kU} / \mathrm{L}$ \\
\hline GST & $3.2 \mathrm{U} / \mathrm{L}$ & $\mathbf{C A 1 5 3}$ & $25 \mathrm{kU} / \mathrm{L}$ \\
\hline ALP & $\sim 0$ & CA27-29 & $36.4 \mathrm{kU} / \mathrm{L}$ \\
\hline SCCA & $1.5 \mu \mathrm{g} / \mathrm{L}$ & $\mathbf{C A 5 4 9}$ & $11 \mathrm{kU} / \mathrm{L}$ \\
\hline Ferritin & $250 \mu \mathrm{g} / \mathrm{L}$ & $\mathbf{C A 1 9 - 9}$ & $37 \mathrm{kU} / \mathrm{L}$ \\
\hline AFP & $10 \mu \mathrm{g} / \mathrm{L}$ & $\mathbf{C A 5 0}$ & $14-20 \mathrm{kU} / \mathrm{L}$ \\
\hline CA242 & $20 \mathrm{kU} / \mathrm{L}$ & $\mathbf{C A 7 2 - 4}$ & $6 \mathrm{kU} / \mathrm{L}$ \\
\hline
\end{tabular}

is very important. Periodically monitoring cancer biomarkers is a necessity and biosensors are the promising tools that can enable us to achieve this. What we need is low cost-user friendly, compact biosensors in liue of huge instruments of astronomic prices present in medical laboratories with simple and instant measurement abilities. If the cost and time per a cancer biomarker check is reduced, these checks can be routinely done for everybody.

Impedance biosensors are electrical sensors that can be miniaturized and suited to these kinds of monitoring applications. Sensitivity and repeatibility is two of the biggest challenges before their commercialization [9]. Future research in this area is expected to overcome these challenges and pave the way for low cost, small size commercial products. These products can help us to detect cancer and start fighting with it earlier.

\section{References}

1. Hossain M, Su M. Nanoparticle Location and Material Dependent Dose Enhancement in X-Ray Radiation Therapy. J Phys Chem C Nanomater Interfaces. 2012;116(43):23047-23052.

2. GLOBOCAN 2008. [Online]. Available: http://globocan.iarc.fr/. Accessed: 07-Jun-2012.

3. Leaf C. Why we're losing the war on cancer (and how to win it). Fortune. 2004;149(84):76-82.

4. Bohunicky B, Mousa SA. Biosensors: the new wave in cancer diagnosis. Nanotechnol Sci Appl. 2010;4:1-10. doi: 10.2147/NSA.S13465.

5. Soper SA, Brown K, Ellington A, Frazier B, Garcia-Manero G, Gau $\mathrm{V}$, et al. Point-of-care biosensor systems for cancer diagnostics/ prognostics. Biosensors and Bioelectronics. Biosens Bioelectron. 2006;15;21(10):1932-42.

6. Cao Y, DePinho RA, Ernst M, Vousden K. Cancer research: past, present and future. Nat Rev Cancer. 2011 ;11(10):749-54. doi: 10.1038/ $\operatorname{nrc3138.}$

7. Nie S, Xing Y, Kim GJ, Simons JW. Nanotechnology Applications in Cancer. Annu Rev Biomed Eng. 2007;9:257-88.

8. Tothill E. Biosensors for cancer markers diagnosis. Seminars in Cell and Developmental Biology. Semin Cell Dev Biol. 2009;20(1):55-62. doi: 10.1016/j.semcdb.2009.01.015.

9. Daniels JS, Pourmand N. Label-Free Impedance Biosensors: Opportunities and Challenges, Electroanalysis. 2007;19(12):12391257. 